\title{
CULTURAS MARÍTIMAS NA COSTA NORTE DO MÉXICO; NATUREZA E COSMOVISÕES EM ALTAMAR. ETNOECOLOGIA E NOVA ETNOGRAFIA
}

\author{
CULTURAS MARITIMNAS, NATURALEZA Y COSMOVISIONES EN ALTAMAR, \\ COSTA NORTE DE MÉXICO
}

\section{MARITIME CULTURES, NATURE AND COSMOVISIONS IN ALTAMAR, NORTH COAST OF MEXICO}

\begin{abstract}
RESUMO
Em Cabo Rojo, o oceano não tem apenas a função de fornecer comida, mas sim o líquido vital ("as águas da vida", como expressam os pescadores) o elemento de que os tempos dependem: experimentação e conhecimento, e a própria existência do espaço biofísico como um todo, do qual os pescadores são inerentes e não algo estranho e independente. Eles desenvolveram uma capacidade connatural para construir complexos culturais, está em estreita relação com esse ambiente natural, o oceano. Desta maneira para estas culturas; o mar é um lugar de geração de vida, de fertilidade, de nascimento, mas também de morte, uma "morada de divindades". O mar é um marco astronômico de pesca e pesca especializada, diretamente ligado ao cosmo; uma interação de tempos, espaços e experiências com o fardo sagrado e profano.
\end{abstract}

Palavras - chave: etnoecologia, etnografia, mito, identidade, território, paisagem, pesca, ritual.

\footnotetext{
${ }^{1}$ CoLaboratório de Oceanografia Social. O Colégio de Michoacán, A.C. Red Temática de Socioecosistemas y Sustentabilidad, Red Temática sobre Patrimonio Biocultural de México, Nodo Mares; Consejo Nacional de Ciencia y Tecnología. Escuela Nacional de Antropología e História. México. Email: paisajeritual@gmail.com
} 


\section{RESUMEN}

En Cabo Rojo, al norte de la Huasteca (en el Norte del Golfo de México, en el Estado de Veracruz) el océano no solo tiene como función proveer de alimento, sino más bien, es el líquido vital, ("las aguas de la vida" como le nombran los pescadores locales) el elemento del que dependen los tiempos: experimentación y conocimiento, y la misma existencia del espacio biofísico en su conjunto del que los hombres pescadores son inherentes y no algo ajeno e independiente. Ellos han elaborado una connatural capacidad para edificar complejos culturales, está en relación estrecha a ese medio natural, el océano. De esta forma para estas culturas, el mar resulta un sitio de generación de vida, de fertilidad, de nacimiento, pero también de muerte, una "morada de deidades". El mar es un marcador astronómico para la pesca y capturas especializadas, la cual se liga directamente con el cosmos; una interacción de tiempos, espacios y experiencias con carga sacra y profana. Este artículo pretende mostrar parte de universo de la pesca y de la vida ritual de los pescadores artesanales de Cabo Rojo conociendo a través de los relatos etnográficos y descripciones detalladas la visión ordenada del tiempo y del espacio, y los procesos enseñanza y aprendizaje (educación socioambiental) que los más jóvenes experimentan en la mar.

Palabras Clave: etnoecología, etnografía, mito, identidad, territorio, paisaje, pesca, ritual.

\section{ABSTRACT}

In Cabo Rojo, north of Huasteca (in the North of the Gulf of Mexico, in the State of Veracruz), the ocean not only has the function of providing food, but rather, it is the vital liquid, ("the waters of the life" as the local fishermen name it) the element on which the times depend: experimentation and knowledge, and the very existence of the biophysical space as a whole from which the fishermen are inherent and not something alien and independent. They have developed a natural capacity to build cultural complexes, it is in close relation to that natural environment, the ocean. In this way for these cultures, the sea is a place of generation of life, fertility, birth, but also death, a "abode of deities." The sea is an astronomical marker for fishing and specialized catches, which is directly linked to the cosmos; an interaction of times, spaces and experiences with sacred and profane load. This article aims to show part of the universe of fishing and the ritual life of the artisanal fishermen of Cabo Rojo, knowing through the ethnographic accounts and detailed descriptions the ordered vision of time and space, and the teaching and learning processes (socioenvironmental education) that the youngest experience at sea.

Key Words: ethnoecology, ethnography, myth, identity, territory, landscape, fishing, ritual. 


\section{INTRODUCCIÓN}

México cuenta con 10,500 km de litoral repartidos entre el Océano Pacífico, el Golfo de México, el Golfo de California y el Mar Caribe. Es un país donde viven de la pesca artesanal 350,000 pescadores y sus familias. Pese a esto, las ciencias sociales - y en particular la antropología mexicana- ha prestado poca atención al estudio de las comunidades costeras que subsisten de los recursos del mar y de la propia actividad pesquera. Al hablar de poblaciones pesqueras en México, nos percatamos que han recibido escasa atención por los antropólogos hasta hace relativamente poco tiempo. Los primeros trabajos monográficos en este campo aparecen a finales de los años ochenta, con planteamientos teóricos cercanos al funcionalismo, sobre todo con el proyecto "La vida en un lance", que tuvo como resultado las publicaciones de 12 monografías sobre la vida de los pescadores de México, si bien fueron los trabajos pioneros, dejaron de lado otras ínfulas de análisis antropológico, como la religiosidad popular, rituales de iniciación en la pesca y mitos que prevalecen en muchas regiones en comunidades pesqueras de nuestro país. Otros paradigmas que han sido utilizados para analizar las poblaciones de pescadores van desde el interaccionismo simbólico a la ecología procesual o la economía política, como los trabajos de Andreas Brockmann (2004), quien, en su trabajo, nos da testimonio de la presencia del mundo marino en las culturas de las comunidades costeras del país, como de aquellas ciudades del interior, donde se ven productos particulares y lenguajes propios de los pueblos pesqueros.

Otras investigaciones en México sobre la problemática pesquera, han sido realizadas desde diferentes disciplinas como la economía, ingeniería, arquitectura, derecho, biología, oceanografía, oceanología, sociología, etc. Por ejemplo, el trabajo de Reyes Ayala Quintero (1980), en el cual, bajo el enfoque de la economía política describe como las comunidades pesqueras se han beneficiado económicamente y políticamente, uniendo lazos y abriendo rutas comerciales entre cooperativistas de varias localidades e incluso regiones.

La biología, por su parte, ha investigado sobre temas que incluyen peces, mamíferos, aves, moluscos, y también, específicamente, sobre la problemática de pesquerías, artes de pesca, capturas incidentales y descarte pesquero (Mateo, 2004), entre otros. La economía por su cuenta, ha indagado sobre la implicancia de los 
movimientos comerciales marítimos. Aunque la pesca no cuente con la misma visibilidad económica-productiva que la actividad agrícola y la ganadera, en nuestro país, gran parte de los ingresos por exportaciones se producen por la pesca.

Hablar sobre los estudios de las comunidades pesqueras desde una perspectiva antropológica tiene una tradición dentro del campo. Consideramos que el estudio de la actividad pesquera en la antropología se encuentra desde sus orígenes, ya que ésta se ha enfocado al estudio de las comunidades primitivas, quienes se dedicaban a la recolección, la caza y la pesca. Es decir, ésta es una de las actividades que el hombre ha realizado desde sus inicios (Cruz, 1996). Podemos mencionar como ejemplo de esto los estudios realizados por Malinowski en las Islas Trobriand (1948), o el de Margaret Mead en Samoa (1928), como unos de los materiales importantes en lo que, años más tarde, serían lecturas necesarias para ir conociendo el trabajo en las comunidades pesqueras.

Los cambios culturales y sociales que se están dando en la zona Cabo Rojo, en general en todo el estado de Veracruz, principalmente debidos a la infraestructura (caminos, puentes, hoteles y desarrollos turísticos), están propiciando el abandono de la propia actividad pesquera, de los ciclos rituales y del culto sagrado al mar. Los registros de estas actividades con carga sacra, han sido nulos, los pocos datos con que se cuenta y los carentes archivos que podemos encontrar en los municipios costeros de la zona para apoyar nuestras observaciones, nos han motivado a escribir un etnografía donde se plasme la identidad, la ideología (Giménez, 2006) y la memoria histórica² (Burke, 2000), donde se rescate la oralidad y donde resaltemos la persistencia de las prácticas mágicas de culto a la naturaleza que aún reproducen a nivel regional los pescadores de esta zona.

Esperamos que la propuesta de esta investigación, por lo que significa para la Antropología Marítima, abra nuevas ínfulas de especialización a los científicos sociales y contribuya a una mejor comprensión de la compleja y rica historia de las comunidades marítimas de nuestra América, su propia percepción y comprensión del mundo. Si los estimados lectores aceptan los materiales como una invitación al estudio crítico de la complejidad cultural en los grupos y regiones donde prevalecen los ecosistemas de marismas, y su significado fundamental para la historia ecológica y social de América Latina, veré realizado el objetivo principal de estos esfuerzos; concentrados en mostrar en el trasfondo, que la educación ambiental en Cabo Rojo consiste en la interrelación de

\footnotetext{
2 Los acontecimientos consignados en este trabajo han sido narrados en su mayoría por los propios pescadores (Historia Oral), familiares de ellos y gente del lugar, gente de edad y gente joven, en este sentido, son ellos los actores principales que dan vida y voz a esta investigación (Rescate de la Memoria Colectiva).
} 
los sujetos menos experimentados con su entorno marítimo, buscando un cambio de actitud, una toma de conciencia sobre la importancia de conservar y salvaguardar para el futuro. La adopción de una actitud consciente ante el medio que nos rodea, y del cual formamos parte indisoluble, depende en Cabo Rojo, en gran medida, de la enseñanza y la educación de la niñez y la juventud.

\section{METODOLOGÍAS}

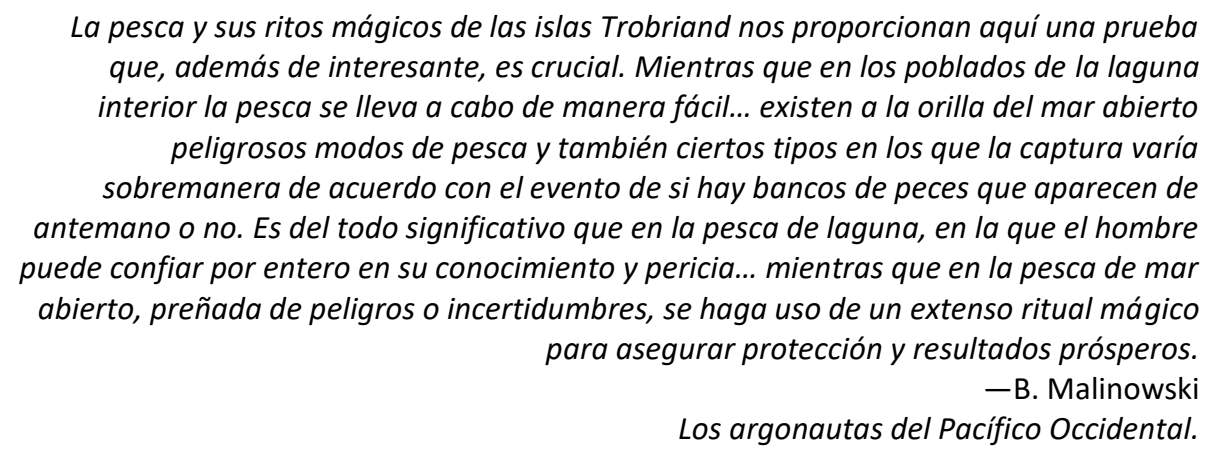

El artículo que aquí se presenta es el resultado de una investigación que inició desde el año 2006 a la fecha (2019) en la zona de Cabo Rojo, donde hemos abordado el tópico de la actividad religiosa de los pescadores desde el punto de vista de la antropología ecológica y en este caso desde la Ecología Cultural y la Historia Social, con la finalidad de situar a través del tiempo, el contexto biocultural actual de esta zona.

Para recolectar algunos de nuestros datos nos valemos de la etnografía, instrumento que potencia la mirada del curioso y del analítico. Consideramos que el etnógrafo es, entonces, un escritor, un creador de imágenes que muestra los caminos de lo que está más allá de lo evidente. Pero también es un ser analítico y observador, especializado en mirar detenidamente y por largo tiempo.

A primera vista la conducción etnográfica parece sencilla, pero no es así, ya que ésta requiere de una gran sensibilidad y una fuerte documentación que le permita al investigador saber actuar en una determinada comunidad, saber discernir acerca de las diferentes problemáticas que se puedan presentar y que merezcan su atención como posible investigación. Existe un desacuerdo sobre si la característica distintiva de la etnografía es el registro del conocimiento cultural y la investigación detallada de patrones de interacción social (Taylor-Bogdan, 1984) o el análisis holístico de sociedades (Atkinson, 1994). Algunas veces la etnografía se define como esencialmente descriptiva, 
o bien como la empleamos para este texto, como una forma de registrar narraciones a través de la oralidad (De Tezanos, 1998) rescatando el conocimiento local y formas de aprendizaje para interrelacionarse con la naturaleza en ecosistemas marítimos.

Han sido muchas las críticas que ha recibido la etnografía; algunos consideran la etnografía como la forma más básica de investigación social, mientras que otros la descalifican, ya que la ven como impropia para las Ciencias Sociales, porque la información que en ella se recoge es "subjetiva". Sin embargo, el estudio etnográfico se ha ido fortaleciendo paulatinamente, debido a la larga historia que tiene la etnografía y a la importancia que ésta presta en la manera como la gente otorga sentido a las cosas de la vida cotidiana y los procesos sociales.

Para llevar a cabo la práctica etnográfica, el investigador debe estar preparado para vincularse a la comunidad que desea conocer, además debe ser una persona que esté dispuesta a acercarse al grupo y que, de igual forma, permita el acercamiento de los miembros del grupo hacia él. El etnógrafo debe saber dónde y cuándo observar, con quién conversar, así como qué información se debe registrar y cómo se debe hacer ${ }^{3}$.

Por otro lado, nos valemos de la herramienta oral para rescatar los relatos y narraciones. La historia oral es la especialidad dentro de la ciencia histórica que utiliza como fuente principal para la reconstrucción del pasado los testimonios orales. A pesar de no tratarse de una técnica de investigación nueva, ya que lleva décadas siendo utilizada en distintos ámbitos, la historia oral supone una aportación bastante innovadora en el conjunto de la historiografía oficial, tanto en su vertiente de la investigación histórica como en lo relativo a la docencia de la propia historia. En palabras de Paul Thompson (1984): "la historia oral es la más nueva y la más antigua forma de hacer historia”. Al vincularse a la comunidad, el investigador puede participar de manera abierta del cotidiano de las personas durante un tiempo relativamente extenso, de manera que puede apreciar con mayor precisión lo que suceda, sus historias de vida y sus procesos de enseñanza-aprendizaje. Es decir, aquel que salvaguarda la oralidad, estará atento, viendo lo que pasó y lo que pasa, escuchando lo que se dijo y dice, lo que cuentan que sucedió, preguntando cosas que puedan interesar para escribir la historia de esas personas y la su comunidad, recogiendo todo tipo de relatos y narraciones que permitan vislumbrar su pasado desde el contexto presente.

\footnotetext{
${ }^{3}$ En esta parte, el investigador debe hacerse amigo de los miembros del grupo, propiciar temas para que sean compartidos, dejando obviamente que la mayoría de las personas que se acerquen a él intervengan o tomen la palabra el mayor número de veces, pues en la conversación es posible que salgan a luz algunos temas o aspectos que interesen para una posible investigación.
} 
Es preciso señalar, que son los propios pescadores quienes proporcionaran la información contenida en este texto. El carácter franco y alegre constituye la virtud más apreciable de los pescadores del Golfo de México. Sobra decir, que la informaciónmaterial de campo se recopiló mediante el método de la expedición itinerante, consistente en visitar todos los puertos de los países citados, siguiendo la misma línea de la costa (riberas oceánicas). Es preciso anotar que la actitud y el comportamiento del investigador en la comunidad debe ser natural, debe relacionarse de la manera más espontánea y tranquila posible, porque puede suceder que algunas personas de la comunidad se sientan observados y cambien su forma de actuar frente al investigador.

Consideramos que la labor de campo solo adquiere sentido a condición de que el investigador se someta a un continuo aprendizaje sacando el mejor partido posible de las experiencias de nuestros interlocutores. Las imágenes que compartimos fueron empleadas para la comprensión y estudio de los sucesos del pasado, muchos de los que llegan a nuestro presente y son por ello motivo de consulta con la gente de tradición o de quienes presenciaron o escucharon diferentes historias orales.

\section{Resultados}

Varias son las sociedades y culturas en la actualidad que viven de lo que la naturaleza les brinda, trabajando con ella y para ella. Tal es el caso de las comunidades del Golfo de México, la parte norte correspondiente a la Huasteca Veracruzana; en la Zona Arrecifal denominada Cabo Rojo, tratando de dilucidar la influencia que la pesca y el medio ambiente ejerce en todos los aconteceres de la vida de sus habitantes, esto es; visiones del mundo, religiosidades, prácticas rituales y un resguardo de la memoria cultural y mítica, identidades y una dimensión simbólica compleja que atiende a ciertas potencias de la naturaleza; la más importante, el agua, el mar.

Desde los tiempos de las sociedades aldeanas, dentro de los cultos que se efectuaban a la naturaleza siempre se exacerbó al agua como un universo de significaciones y realidades (León-Portilla, 1992), el agua formó parte de las creencias mágicas, pues se le concebía como una serpiente acuática que era el espíritu de las aguas terrestres, lo mismo que como una serpiente alada que simbolizaba a la nube de lluvia. Rico en símbolos fue lo que pensaron los mayas, las gentes de idioma náhuatl, los mixtecas y otros pueblos relacionándola con el origen cósmico; se sabía que falto de agua nada nace, ni echa brotes, nada crece y no da frutos, sin el agua el hombre no 
puede existir, impensable era para los mesoamericanos poder existir alejados del agua (León-Portilla, op cit). Así como los antiguos contemplaban que la vida de la comunidad era impensable sin el don de las aguas, el hombre de Cabo Rojo considera que sin el agua, sin el mar, el ser humano como persona, no puede existir, ni física, ni espiritualmente, es el líquido de vida, temido y respetado, quien guía sus vidas, quien decide su existencia como hombres del mar. La biodiversidad existente en esta región, por su complejidad, ha llevado al pescador a conocerla mejor, permitiendo de esta forma diversas lecturas de su comportamiento y una mejor relación sociedad-naturaleza. Con ceremonias, ritos, ofrendas y tecnologías que regulan su ecosistema; los pescadores de estas aguas; rinden culto a su paisaje, al océano; actos humanos que simbolizan una expresión de reciprocidad por lo que reciben de él.

Analizar los aspectos más sobresalientes de un pueblo pesquero y al mismo tiempo observar sus religiosidad y su relación con la naturaleza, en el contexto actual, nos permitió vislumbrar una serie de aspectos que hasta ese momento no se habían contemplado en los estudios antropológicos de pesca en México, como ha sido la cosmovisión y la vida ritual del pescador de Cabo Rojo. De este modo nos percatamos del trabajo imprescindible, pues la pesca constituye desde épocas antiguas, un enfrentamiento con la naturaleza, conocimiento y adaptación a ella. Para ello el pescador de Cabo Rojo, ha creado una serie de mitos e historias mágicas, las cuales materializa y expresa en sus rituales sagrados, haciendo de su trabajo una forma de vida con rasgos ceremoniales, es decir, una labor sagrada de subsistencia. Para explicar lo anterior recurriremos a los trabajos antropológicos que se han dedicado a estudiar a los hombres, a las sociedades y su relación con la naturaleza mediata.

Es preciso señalar que desde épocas prehispánicas, la religión ha formado una parte importante de la sociedad y en ella se reflejaban muchas actividades cotidianas y conceptos acerca de la vida de los hombres, y se expresaban reflexiones filosóficas más complejas acerca del destino del hombre y su lugar en el cosmos (Broda, 1991). Las antiguas culturas mesoamericanas heredaron una prolongada y sistemática tradición de observación de la naturaleza que incluía muchos elementos "científicos", en el sentido de un registro deliberado y repetido a lo largo del tiempo de los fenómenos naturales del medio, que permitía a los especialistas (ceremonialistas, sacerdotes, brujos, curanderos, etc.) hacer predicciones y orientar el comportamiento social de acuerdo con estos conocimientos. Sin embargo, a diferencia de las sociedades industrializadas modernas, la 
observación de la naturaleza no era una actividad profana, sino que estaba ligada a la religión y la magia (Broda, op. cit.). En términos más amplios, para las sociedades mesoamericanas la integración con la naturaleza constituía un propósito importante, y los rituales y las prácticas religiosas buscaban mantener los equilibrios y vivir en armonía con la naturaleza.

Repensar a estas sociedades marítimas desde su contexto cultural y religioso ha sido un tema nulamente explorado, más aún, si se profundiza en la relación que tienen los hombres con su entorno natural en el contexto actual. Escribir sobre el medio ambiente y el pasado, obliga a recorrer todos los tiempos, porque allí, en el mar, el ser humano traspasa los tiempos y espacios cotidianos, para acceder a los ciclos y recintos de las deidades que custodian y rigen el entorno. En las comunidades marítimas de Cabo Rojo, es importante comprender que el océano no solo tiene como función proveer de alimento, sino más bien, es el líquido vital - las aguas de la vida como le llaman los pescadores de la zona - el elemento del que dependen los tiempos: experimentación y conocimiento, y la misma existencia del espacio biofísico en su conjunto del que los hombres pescadores son inherentes y no algo ajeno e independiente. El mar resulta, así un marcador astronómico para la pesca y capturas especializadas, la cual se liga directamente con el cosmos; una interacción de tiempos, espacios y experiencias con carga sacra y profana. Ellos, han elaborado una connatural capacidad para edificar complejos culturales, está, en relación estrecha a ese medio natural, el océano. Para estas culturas que habitan en ecosistemas de marismas; el mar resulta un sitio de generación de vida, de fertilidad, de nacimiento, pero también de muerte, una morada de deidades.

Al nacer, en los municipios y localidades de Cabo Rojo, más aún, si se es hijo de un pescador, el agua es entregada como un regalo, pues ha sido concedida a ellos por obra de los dioses. Es notable ver que cuando se aproxima un nacimiento, las parteras acarrean agua de mar o de la laguna en algún recipiente, la bendicen orando ante ella y cuando se recibe a la personita se le otorga rociándola y purificándola con el agua de mar o de laguna, se cree que es el mar quien envía a esta nueva persona, quien le brindó la existencia, y por ello es él quien a la vez debe recibirla (Reynoso, 2011). Por otro lado en las dos aguas existentes en la zona de Cabo Rojo (Mar y Laguna), el hombre se desarrolla y crea su conocimiento; conocimiento que viene del pueblo y va hacia él, otorgándole creencias, identidad y simbolismo. La iniciación en la pesca comienza desde 
muy pequeños, a los niños se les cuenta historias y anécdotas mágico-religiosas acerca del mundo del pescador y a lo que se enfrentarán, son los ancianos los que más narran sucesos y transmiten experiencias en el oficio en la mar, orientándolos acerca de los riesgos, obligaciones y responsivas que un día deberán asumir, tanto en la laguna como en el mar, y de las precauciones que deben tomarse en situaciones de peligro, así como explicaciones necesarias para que cuiden y respeten su medio natural. De esta forma les enseñan sobre los ciclos marinos, las fases lunares, las especies marinas que existen en cada zona y sus temporadas, el vuelo de las aves marinas, el temperamento de las aguas y vientos, etc.; son detalles fundamentales que desde antes deben tener en cuenta. Es así que los tránsitos intermedios, a los que se enfrentan los jóvenes pescadores, tiene que ver con enseñanzas-aprendizajes y múltiples etapas en la vida, consistentes en la integración en el mundo de los adultos, en el mundo del pescador productivo que lee, se comunica, se interrelaciona, valoriza e interioriza, re simboliza, maneja y comprende su medio vital, el mar. En este sentido, la función ritual de estas experiencias iniciáticas es la de permitir las transiciones necesarias entre territorios, tiempos o situaciones sociales diferentes.

Estas experiencias iniciáticas en lo que será su integración al mundo de la pesca, son muy importantes en Cabo Rojo, puesto que tienen que ver con la enseñanza del orden social establecido que rige el mundo del pescador de esta zona, pues desde su condición como niños, estos infantes aceptan una forma y estilo de vida, que después del tiempo y de lograr experiencia y conocimientos, se consolidarán a futuro como trabajadores del mar. Los adolescentes no son ni lo uno, ni lo otro, ni adultos, ni pescadores, así se presentara como obligatorio en el futuro cercano la ritualización del tránsito formal, legítimo y sagrado de esta etapa; la vida ceremonial se expresa de manera contundente en estos rituales de la pesca, donde el joven deja de ser niño, trasciende al status de adulto, y donde el niño deja de ser un ente mundano, para convertirse en un trabajador del mar, en un pescador, en palabras de los propios pescadores un "hijo del océano". De resumida forma presentamos los rituales de iniciación en mar y laguna:

Iniciación en la mar: Este ritual consiste en llevar al joven candidato a lo lejano del océano, allí rodeado de mar inicia el ritual, el lugar es elegido por el especialista de igual forma lo acompañan sus padres y un conocido, que va a cumplir el rol de padrino o testigo del acontecimiento, quien previamente ha construido un collar de conchas y 
caracoles que otorgara al final del ritual al joven pescador. El especialista lleva consigo ciertas hierbas previamente preparadas en un recipiente, las cuales unta en el pecho del joven, frotando y diciendo: "te entrego a este hijo tuyo, ahora se unirá contigo y le darás de lo tuyo", después de esto, el padre corta con un anzuelo la palma derecha de la mano del joven en forma horizontal, la cortada en ocasiones es profunda y el sangrado es abundante, al mismo tiempo que sucede esto, el padre toma la mano y derrama la sangre en el mar, esparciéndola en él, el joven debe aguantar el dolor y la molestia, finalmente el especialista dice: "ahora ya eres parte de la naturaleza y cumplirás como hombre con tus quehaceres", el padrino acude con el joven a quien su madre le limpia y le lava la herida con agua del propio mar, y le coloca el collar que le ha construido, lo pone en su cuello y dice: "recibe estos caracoles que te protegerán están bendecidos por el mar y la tierra, limpiados por el viento".

Iniciación en la laguna: A los jóvenes que desean integrarse en la vida productiva de la pesca en la laguna, se les lleva a confesar con el sacerdote (casi siempre católico) días antes, con la finalidad de que se presenten "limpios de ideas malignas" ante la clara naturaleza de la laguna; puesto que la idea que poseen este tipo de pescadores de ella es de pureza y claridad, la laguna recibirá al joven limpio al igual que ella, pues es necesario, dicen los pescadores, "para poder unirse a ella". El ritual inicia desde que el joven se confiesa ante el sacerdote católico, una vez realizado esto se parte hacia el corazón de la laguna, una distancia bastante extensa es la que recorren, pues en esta parte de la laguna la pesca es nula. Después de dos horas de recorrido nos acercamos al lugar sagrado en la laguna, una vez allí el especialista, los padres del joven candidato a pescador y acompañantes (padre, madre y padrinos) se ponen de pie con suma precaución en el bote, se apaga por completo el motor, se ancla el bote, el equilibrio es necesario, la alegría de los presentes se hace notar, el paisaje natural, roba la mirada y se pierde entre tanta agua, lejanos islotes, lejanos mangles, las aves pasan y sobrevuelan el bote, pareciera ser que todos los seres vivientes allí presentes acudieran al ritual y participasen en él, la naturaleza que se exhibe brinda tranquilidad, el pensamiento viaja, se olvida de pronto porque vinimos hasta acá, pero el especialista como un guía acude a nosotros y nos pide atención, pues el ritual está a punto de iniciar. El joven se desnuda, mientras los padres se ponen sobre cuclillas en el bote, siguiendo las palabras del especialista quien dice: "te hemos traído a esta persona, pura de corazón para que sea recibida por tus claras aguas, para que pesque aquí y lo protejas”, después 
es untado en la cabeza y manos de restos de pescado, los cuales son traídos y lavados antes por la madre del muchacho; y como si fuese un anzuelo impregnado con el aroma y restos del pez muerto en cabeza y manos es arrojado a la laguna por el especialista, nadando y pataleando en lo profundo de la laguna, casi a punto de ahogarse, mientras los padres espantados sin poder intervenir repiten junto al especialista: "tómalo aquí y comprueba que es puro, ahora ya es parte de ti y vendrá a visitarle y a pescar, todos te agradecemos", después de esto e inmediatamente se saca del agua al joven que en ocasiones yace agotado y casi ahogado, lo reciben sus padres a punto de llanto le secan y lo abrazan, la sonrisa vuelve a ellos, lo duro ha pasado, el especialista lo felicita, y es hora contemplar de nuevo la naturaleza, se cree que una vez en el agua el joven debe luchar solo y sobrevivir.

Estos mismos rituales nos fueron relatados por Tony, pescador nativo de tan sólo 15 años, él asegura que la sensación de yacer unos minutos bajo el agua transparente de la laguna es de terror, no importando lo mucho que se sepa nadar la laguna te absorbe, "te prueba" dice Tony, por ello el hecho de untar restos de pescado en cabeza y manos, cuando la laguna te acepta "sientes que desde las profundidades te empujan y sales, y ya están las manos de tu familia secándote y ya respiras". Además se considera que los restos que se untan son para bendecir la cabeza, el pensamiento y contar con inteligencia para aprender de la naturaleza y ser prudentes con ella, de igual forma las manos, pues con ellas se sacara de la laguna el alimento para su familia, afirma Tony que después de salir de la laguna la naturaleza, el medio se vive diferente: "cuando sales sientes que ahora los pájaros, el viento, la tierra, la propia laguna, la marea, y los árboles lejanos te llaman y te dicen cosas, como si cobraran vida", es este ritual de iniciación el que abre las puertas al pescador de laguna para ser "tocado", inspirado, sensibilizado, concientizado, sobre el medio en el que vive, ahora ya es pescador, ahora puede entablar diálogo con la naturaleza.

Un ejemplo más sobre los aspectos históricos y la compleja vida ceremonial de los hombres pescadores de Cabo Rojo, lo representa la vida ritual en la comunidad denominada Majahua, al sur del municipio costero de Tampico Alto, es sin lugar a dudas particular y característica. Pues la actividad de la pesca en alta mar, es considerada una actividad de caza, la llamada caza-pesca del tiburón blanco del Golfo (Carcharodon carcharias), y la langosta (Panulirus argus), especie de gran volumen, característica de la región arrecifal del golfo. Entre todas las costumbre de estas comunidades y villas de 
pescadores, con un estilo y forma de pensar no occidental que abren un abismo entre sus plasmaciones culturales y las nuestras; en Majahua las más representativas son aquellas donde figura el dar muerte a los animales, y es la misma la que refuerza nuestra afirmación sobre su actividad marítima en altamar: la caza ritual del tiburón y su sacrificio en el marco de determinadas ceremonias para la buena fortuna, prosperidad, fertilidad y abundancia. En nuestras estancias en la comunidad de Majahua (2015 a 2019) hemos podido observar que en la actividad de la pesca de sus especies locales (tiburón y langosta) indudablemente lo que importa, esencialmente, es el acto mismo de matar, de dar muerte al tiburón. Es preciso señalar que en los casos mesoamericanos donde se han encontrado sacrificios de animales, casi siempre son animales domesticados, porque se trata de culturas que cultivan la tierra (Vargas Pacheco, 1993). Sin embargo en Cabo Rojo, en las villas de pescadores y muy particularmente en Majahua, los animales existentes yacen en lo profundo y lejano del océano, son a ellos a los que la gente rinde culto y respeto, y son los mismos, por su condición de "salvajes y naturales", los que deben ser sacrificados para que el hombre pescador de Majahua sobreviva, igual que sus seres divinos, pues la carne de tiburón, muchas veces es ofrendada a entidades sobrenaturales, y desde luego, para el consumo humano, de igual forma es característico que el animal acuático sea llevado aún vivo al lugar de culto, para ser sacrificado ahí.

Precisamos que salvo las crías de tiburones más pequeñas son las destinadas a ofrendar y donde la muerte definitiva del animal acuático, ocurre en el lugar de culto, que puede ser un ojo de agua o un estero cercano a la playa; sin embargo, una vez más, se expresa el hecho de que lo que importa de modo decisivo entre estos pescadores es dar muerte a su presa. Así la participación venturosa en la caza-pesca de tiburón a menudo constituye el supuesto previo de la capacidad de un joven pescador de Majahua para entablar relaciones matrimoniales con alguna bella lugareña de la ribera del pueblo, siendo totalmente indiferente que posea un trofeo mandibular y reconocimiento, porque lo decisivo es el hecho y la capacidad para cazar-pescar y darle muerte al tiburón; para ello se requiere un bote de madera ligero, canalete, en ocasiones redes o atarrayas, y siempre, tan solo una lanza apuntada, gruesa, fina y ligera, hechas de madera y punta de acero. Durante la festividad del el día del pescador (25 de junio) los pescadores de esta localidad, aparte de integrarse a las festividades y demás cultos llevados a cabo en los municipios cercanos, realizan ciertas celebraciones con carga religiosa donde llevan a cabo un "computo de caserías de tiburón"; en el que se atribuye a cada una de ellas un 
determinado número de "puntos" valorándose las muertes; por ejemplo, quien allá cazado en 5 a 10 años mayor presas (que pueden ser desde 2 a 5 tiburones máximo en 5 años y 10 a 25 tiburones en 10 años) y de mayor volumen, es quien recibe mayor reconocimiento en el pueblo y la posesión de trofeos y prestigio y reconocimiento social, son decisivos. A ello acude una lógica de fertilidad y transición social, pues quien haya cazado su primer tiburón está listo para procrear, es decir, quien: "allá matado, que mate, quien no ha procreado, que procree, se debe ser primero, un buen cazador, un buen pescador, así se podrá alimentar a la familia y ayudar a la comunidad.”

Otros de los rituales que llevan a cabo los pescadores de esta comunidad con la finalidad de obtener suerte y buena fortuna en sus capturas, consiste en quemar conchas de caracol molidas, revueltas con pequeños colmillos de tiburón, dichos materiales son depositados en un recipiente pequeño de barro, a los cuales, posteriormente se les agrega agua de mar, de lluvia, laguna y de esteros, una pequeña cantidad de cada una, cuando están hirviendo y el agua es casi consumida por el calor de las brasas y llamas de pino (Abies religiosa) seco, se vierte sangre de tortuga (Lepidochelys olivácea); una vez que la sangre se quema junto con la mezcla, los filosos colmillos que yacen en el fondo de la pequeña vasija, cambian drásticamente de color, en ocasiones se ponen negros, en ocasiones adquieren un color rojo y otras veces presenciamos que adquieren un color amarillento; se cree que con este ritual y haciendo dicha mezcla las especies marinas vuelven a la vida, gracias a la sangre de tortuga, pues fungen como líquidos vitales de vida, junto con los distintos tipos de agua.

Después, los colmillos de tiburón son sacados del recipiente, y se analizan por el ritualista, si adquirieron un color diferente al color hueso natural, entonces, quiere decir que la especie ha vuelto a la vida, y yace esperándolos en el mar. Nuevamente, presenciamos un oráculo adivinatorio para saber en tierra a priori, si abra buena pesca, buena captura y/o cacería del tiburón y la langosta (por ello las conchas, las cuales también adquieren un color rojizo, así se sabrá también, si están listas para ser capturadas). El ritual que acabamos de narrar, consiste pues, en invertir de poder a los materiales orgánicos acuáticos, de forma que estos sean capaces de conferir vida; entendiéndose por vida, a la prosperidad, fertilidad y abundancia de las especies marinas de las que ellos dependen.

Como podemos ver en estos relatos etnográficos (rituales de iniciación), las metas de dichos rituales, expresadas en palabras ocultas o en símbolos, estructura las 
relaciones durante cierto periodo temporal. En este caso, hemos podido observar que estas experiencias formativas y transformativas; son altamente personales, sin embargo son legitimadas por una colectividad, ya que el ritual muestra a los jóvenes lo que se puede decir, lo que se trata de mostrar y enseñar, en este sentido es eficiente las relaciones estructurantes de la cultura local que expone en su trasfondo, así, el ritual transmite y comunica las cosas y los símbolos que de otra manera serian difíciles y hasta imposibles de mostrar.

La trascendencia de los estudios marítimo sociales en Cabo Rojo radican en la importancia que tiene la pesca ribereña o artesanal, el culto y la relación mágico religiosa que entablan los pescadores con sus aguas: lagunas, esteros, ríos, riachuelos, ojos de agua, océanos, litorales; no solo en México, sino, en gran parte de los océanos del mundo; para este caso el Golfo de México, principalmente. Cabe mencionar, que estos ecosistemas de marismas, son considerados como los más productivos de la biosfera, ya que hoy día están sometidos a una intensa explotación por la diversidad y complejidad de sus recursos biológicos y minerales y por su potencial turístico. Estos ecosistemas son de una enorme complejidad tanto natural, como cultural, y por tanto susceptibles al deterioro y transformaciones, provocados, entre otras cosas, por la falta de gestión de sus recursos renovables, la contaminación y la marginación social de las poblaciones que derivan se subsistencia de la pesca, la caza y la recolección. Advertimos que por estas razones y otras más, es importante atender e insistir que el océano y los cuerpos de agua dulce constituyen un medio de vida sumamente vulnerable. Consideramos que este problema, se presenta en todas las zonas cercanas a las ciudades importantes, e irá agravándose a medida que aumente la urbanización, y los proyectos de industrialización.

Como se aprecia en las descripciones etnográficas, los aspectos religiosos y rituales de la pesca en Cabo Rojo corresponden al universo abstracto, esto es, a los mitos, los cuales se materializan en el universo y práctica ritual, lo cual genera una ideología de lo sagrado, un culto, con un lenguaje simbólico particular, rico en símbolos y objetos sagrados, con sitios sacros, donde se relaciona el trabajo con la vida ritual y ceremonial, con ofrendas, con energía y emotividad, con fe y amor, es con lo que su trabajo toma un aspecto sagrado. Lo emotivo brinda valor al trabajo y a la vez ganancia. Esta lógica de contemplar el trabajo como una labor sagrada, es una estrategia para encontrar y construir un imaginario para actuar. Lo cual los integra culturalmente, brinda seguridad y fortalece el grupo. En este sentido las relaciones 
sociales, las relaciones económicas, y la memoria histórica, se muestran expresivas para realizar en comunidad su labor en la mar. Las estrategias sociales en costa norte de la Huasteca Veracruzana, han permitido que se incorpore una ideología en el trasfondo, la cual hace posible la transformación sociedad sin naturaleza. De esta forma, podemos entender cómo cada sociedad se apropia de un espacio y lo transforma, es el medio ambiente el condicionante cultural que otorga ciertas características a los ciclos sociales y los regula mítica, política y económicamente. De esta forma, el pescador de la región, la naturaleza mediata y las divinidades forman una simbiosis, un Sistema Biótico Ritual donde a la vez que el medio natural modela el pensamiento religioso, el hombre proyecta su imagen para halagar a las deidades creadoras. En el caso de los pueblos pescadores de la Huasteca Veracruzana, se vislumbra como han edificado una importante cultura - como gente del mar- a lo largo y ancho de su región, donde es perceptible el equilibrio entre sociedad y naturaleza.

Es notable ver, que algunos principios básicos de la antigua cosmovisión mesoamericana siguen reproduciéndose en muchas partes de México, si bien con características y elementos diversos, re contextualizados, re utilizados, re significados y re valorados, podemos ver aún, que existen sociedades que siguen entablando un diálogo directo con su medio natural, y que, a partir de la observación precisa de la naturaleza, lo ritualizan y lo transformaban. Tal es el caso de nuestros pescadores de la Huasteca Veracruzana. En esta región costera del Golfo de México, el elemento más importante es el agua de océano que fluye, a veces tranquila, a veces turbulenta, la cual representa la esencia de las aguas primordiales de donde surgió toda la manifestación viviente. El eje, cual columna articuladora es la Laguna de Tamiahua; un símbolo asociado al cambio y a la transformación, a la vida y a la muerte. Una laguna que de alguna forma condiciona y organiza la forma en que las diversas villas de pescadores se apropian del espacio y edifican su sistema social soportado en el complejo fluvial.

El agua del océano, ha sido divinizada en todas sus variantes, como lluvia fertilizadora de la tierra y de los hombres, como corriente en descenso, como agua que inunda y fertiliza, que quita y da vida, que brinda alimento, conocimiento. De esta forma la cosmovisión de la región, al igual que la mesoamericana, tiene como núcleo la concepción del equilibrio dinámico con la naturaleza, ya que ellos consideran que no es su entorno, sino la vida misma. Los pueblos pescadores de la huasteca, como muchos otros asentados en las cuencas, riberas y espacios lacustres, han aprendido a edificar y 
vivir en simbiosis con los elementos naturales que ven como reacción y respuesta de la voluntad de las divinidades, cuyos atributos se corresponden con el fenómeno natural. Esta representación, ha permitido el desarrollo de sociedades que lejos de separarse de la naturaleza, como la sociedad industrial de hoy día, mantienen un estrecho vínculo con océano que se percibe como un ser vivo e integral.

\section{CONSIDERACIONES FINALES}

Cada día cobra mayor interés la investigación socioambiental en México y el mundo. Tal hecho encuentra su explicación en muy diferentes motivaciones: la constatación de que el conocimiento, manejo y utilización tradicionales de nuestros recursos bióticos están sustentados en una sabiduría nada despreciable; la comprobación de que la aplicación de la tecnología científica moderna no siempre resuelve satisfactoriamente (por los riesgos económicos, ecológicos y sociales que frecuentemente implica) las necesidades de alimentación, de abrigo y de salud de nuestro pueblo; la convicción de que los conocimientos locales pueden ser estudiados, desarrollados y aplicados de nuevo, tanto en sus regiones de origen como en otras, mediante el concurso intelectual y laboral de las comunidades dispuestas a experimentarlos y la necesidad de encontrar en la pluralidad innegable de nuestros regionales modos de ser, de hacer y de pensar y en el respeto mismo a dicha pluralidad, una de las partes más sanas del vínculo ideológico de nuestra nacionalidad, son algunas de las razones aducidas para fomentar la producción en este campo de estudio situado entre los que formalmente comprenden por una parte, a las Ciencias Biológicas y por otra a las Ciencias Sociales, pensar en su integración y en sus límites, supone un reto en el que todos debemos trabajar.

Cómo se logra observar en los casos presentados, en Cabo Rojo se requiere del ritual para consumar la eficacia del saber local. Solo mediante el ritual, los pescadores se integran en un lugar oportuno en el cosmos lo cual es importante para conocer el hábitat y la ecología de la región, es decir, sólo mediante estas experiencias iniciáticas jóvenes y adultos conocen de forma profunda el ecosistema marino. Una etapa crucial en la conformación del conocimiento ecológico local, radica en la importancia y reproducción de las prácticas simbólicas y culturales que llevan a cabo en la mar. Finalizando, comentamos que un viejo pescador tiburonero nativo de la comunidad 
ribereña de Majahua, al norte de Veracruz, nos comentó cierta ocasión que conocer es "abrirse hacia un mundo específico a fin de buscar una compensación a nuestros males", nos compartió también que "se debe que humanizar la naturaleza, para naturalizar al hombre".

\section{REFERENCIAS}

AYALA, R. Q. Observaciones críticas sobre el sistema cooperativo. El caso de las cooperativas pesqueras. México: Universidad Autónoma de México. Facultad de Economía, 1980.

ATKINSON, P. Etnografía. Métodos de investigación. Barcelona: Paidós, 1994.

BRODA, J. Cosmovisión y observación de la naturaleza: El ejemplo del culto a las colinas, el Arco Astronómico y la Etnoastronomía en Mesoamérica. México: IIH / UNAM, 1991.

BURKE, P. Formas de historia cultural. Barcelona: Editorial Alianza, 2000.

BROCKMANN. A. La pesca indígena en México. México: Universidad Nacional Autónoma de México, Instituto de Investigaciones Antropológicas, 2004.

CRUZ, J. Mitos y Realidades de la Pesca en México: una perspectiva social. México: Universidad Autónoma de Tamaulipas, 1996.

DE TEZANOS, A. Una etnografía de la etnografía. Aproximaciones metodológicas para la enseñanza del enfoque cualitativo-interpretativo para la investigación social. Bogotá: Antropos, 1998.

GIMÉNEZ, M. Teoría y análisis de la cultura. Volumen I. México: CONACULTA, Instituto Coahuilense de Cultura, Colección Interacciones, 2006.

LEÓN-PORTILLA, M. Agua: universo de significados y realidades, Conocimiento mesoamericano. México: UNAM, 1992.

MEAD M. Adolescencia, sexo y cultura en Samoa. Argentina: Alfa, 1928.

MALINOWSKI, B. Los argonautas del Pacífico occidental. Barcelona: Eds. Península, 1948.

MATEO, J. Personas que viven en el mar. La génesis y el desarrollo de una sociedad marítima y una comunidad pesquera. Rosario: Prohistoria, 2004.

REYNOSO, R. Los Pescadores de Tamiahua, Veracruz: Cosmovisión y Existencia en el Mar. México: Instituto Nacional de Antropología e Historia, 2011.

THOMPSON, P. La historia oral y el historiador. España: Debats Magazine, 1984. 
TAYLOR, S., BOGDAN, R. Introducción a los métodos cualitativos de investigación. Barcelona: Paidós, 1984.

VARGAS PACHECO, E. Sociedad y Naturaleza. Una aproximación al mundo maya a través de la arqueología, la lingüística y las fuentes históricas. México: Universidad Autónoma de México, 1993. 